\title{
Development of fast and accurate algorithm to extract the five parameters of photovoltaic modules
}

\author{
Hisham Haider Yusef Saád ${ }^{1}$, Syafrudin Masri ${ }^{2}$, Abdul-Malik Haider Yusef Saad ${ }^{3}$, \\ Ashraf Bani Ahmad ${ }^{4}$, Tole Sutikno ${ }^{5}$ \\ ${ }^{1}$ Faculty of Computer Science \& IT, Alrazi University, Sana'a, Yemen \\ ${ }^{2,3,4}$ School of Electrical \& Electronics Engineering, Universiti Sains Malaysia (USM), Malaysia \\ ${ }^{5}$ Department of Electrical Engineering, Universitas Ahmad Dahlan, Yogyakarta, Indonesia
}

\begin{tabular}{|c|c|}
\hline Article Info & ABSTRACT \\
\hline Article history: & The mathematical model of a photovoltaic (PV) cell helps in analyzing the PV \\
\hline Received Aug 17, 2019 & $\begin{array}{l}\text { system performance easily. In this paper, a new algorithm is developed to } \\
\text { determine the values of five parameters model of photovoltaic module. }\end{array}$ \\
\hline Revised Oct 30, 2019 & The proposed method which is called extract the five parameters \\
\hline Accepted Dec 3, 2019 & $\begin{array}{l}\text { of photovoltaic modules (EFPPM) is used to find the optimum values of } \\
\text { the I-V equation's parameters that fit with I-V curve. This method reduces }\end{array}$ \\
\hline Keywords: & $\begin{array}{l}\text { the computation time of finding the values of PV model parameters. } \\
\text { The proposed algorithm does not only reduce the computation time but it }\end{array}$ \\
\hline $\mathrm{I}-\mathrm{V}$ and $\mathrm{P}-\mathrm{V}$ curve & provides accurate values of PV model's parameters. A comparison with \\
\hline Photovoltaic & $\begin{array}{l}\text { conventional algorithm shows superiority of the proposed EFPPM in term of } \\
\text { computation speed. The results show that the reduction of the computation }\end{array}$ \\
\hline PV array & time reach nearly twenty-one times faster. The results also clarify that the I-V \\
\hline PV modelling & and P-V curves of EFPPM are exactly the same as provided by data sheets \\
\hline
\end{tabular}

This is an open access article under the CC BY-SA license.

\section{Corresponding Author:}

Abdul-Malik Haider Yusef Saad,

School of Electrical \& Electronics Engineering,

Universiti Sains Malaysia (USM),

14300, Nibong Tebal, Penang, Malaysia.

Email: eng.abdulmalik@gmail.com

$\begin{array}{ll}\text { NOMENCLATURE } \\ \text { a } & \text { Ideality factor of the diode } \\ G & \text { Solar irradiation } \\ G_{n} & \text { Solar irradiation at STC condition } \\ \mathrm{fI} & \text { Output current of PV cell } \\ I_{d} & \text { Shockley diode current } \\ I_{m p} & \text { Current of the cell at MPP } \\ I_{o} & \text { Reverse saturation current of the cell } \\ I_{o, n} & \text { Nominal reverse saturation current of the cell at STC condition } \\ I_{p v} & \text { Incident light current of the cell } \\ I_{p v, n} & \text { Nominal incident light current of the cell at STC condition } \\ I_{s c} & \text { Short circuit current of the cell } \\ I_{s c, n} & \text { Nominal short circuit current of the cell at STC condition } \\ \mathrm{k} & \text { Boltzmann constant }\left(\mathrm{k}=1.3806503 * 10^{-23} \mathrm{~J} / \mathrm{K}\right) \\ \mathrm{KCL} & \text { Kirchhoff's current law }(\mathrm{KCL}) \\ K_{i} & \text { Temperature coefficient of } I_{s c} \\ K_{v} & \text { Temperature coefficient of } V_{o c}\end{array}$




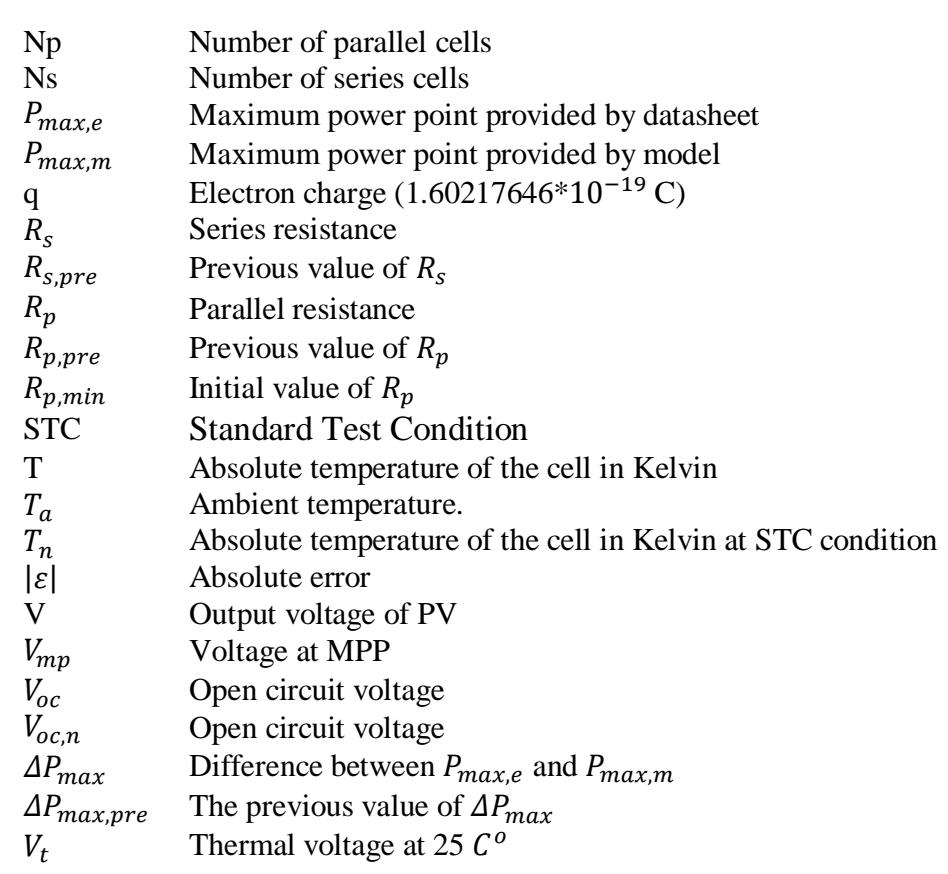

\section{INTRODUCTION}

A remarkable percentage of the used energy is produced by the fossil fuel. The $\mathrm{CO}_{2}$ and many other harmful gases that produced as a result of the fuel's combustion cause many problems to the earth's environment such as Global Warming. Meanwhile, some studies prove that the fossil fuel has an end, therefore, the earth needs alternative energy resources. Sun is one of the most remarkable and renewable energy resources which can produce a useable clean energy. The Sun gives us (approximately) 170 PW [1]. Solar energy might not be the best solution nowadays because of the high cost but it might be for our future generation. Furthermore, a study shows that the renewable resources are growing fast and they become the second largest sources in 2015 and the first energy resources in 2035 [2]. Solar energy is the fastest growing source among them and it doubles each two years [3].

Solar cells convert the light from the sun into DC electrical energy and this occurs in some materials which have the ability to capture photons and release electrons and then current flows. Silicon is the main material in the industry to produce photovoltaic (PV) modules. In this paper, mathematical modelling is used in order to analyse the performance characteristics of the PV modules. Using the mathematical modelling makes the analysis much easier in contrast to the physical modelling [4]. By making mathematical modelling for the PV modules, manipulating and changing the parameters of a given module are easily achieved [5].

The output values (voltage, current and power) of PV models depend on irradiation, temperature and load current. The variations of these (irradiation, temperature and load current) play an important role in the modelling [6]. The single-diode model is not the only available model. In some papers, two and three-diode models are presented. The two-diode model in [7-11] is used for having higher accuracy. The second diode is added to involve the effect of the carrier recombination. The third diode is added in the three-diode model in [12] to involve the missing effects in the two-diode model. Single-diode model [13] is the most popular model because of the simplicity. It is categorized into two types which are four-parameter and five-parameter models. These five parameters including the parallel resistance are series resistance, incident light current, diode reverse saturation current, and ideality factor. The five-parameter model is considered more accurate and widely applied than the four-parameter model [14].

To extract these five parameters, several methods were applied. One method is to identify the parameters using the curve-fitting for the experimental data collected under specially controlled environment (SCE) such as sun simulator [8]. Deferent methods such as neural network (NN) and neuro-fuzzy model are used. NN model $[15,16]$ has a drawback which is the need of much data for training the neural network while neuro-fuzzy model needs fewer data [17].

Another method is to extract the parameters from driven equations with the help of the electrical specification data of the solar module provided in datasheets $[18,19]$, which are: the nominal short-circuit current $\left(I_{s c, n}\right)$, nominal open-circuit voltage $\left(V_{o c, n}\right)$, experimental peak output power $\left(P_{\text {max }, e}\right)$, voltage at MPP $\left(V_{m p p}\right)$, current at MPP $\left(I_{m p p}\right)$, the temperature coefficient of the open-circuit voltage $\left(K_{v}\right)$, the temperature coefficient of the short-circuit current $\left(K_{i}\right)$ and the temperature at the nominal operating cell 
temperature (NOCT) under Standard Test Condition (STC). This method is much more reliable because the parameters of the model are computed mathematically using reliable data (datasheet). Therefore, it produces more accurate models, but in the price of time. It uses iteration methods, therefore, it consume too much time to find the model parameters. This paper tries to solve the unbearable time-consumption. In the meantime, it produces an accurate model. In this paper, we start with the methodology that includes model of a solar cell and the proposed modelling algorithm (section 2). Then, KC200GT solar array is used in section 3 to examine the EFPPM's accuracy and speed and compare with Villalva's modelling algorithm [24]. Lastly, section 4 displays the conclusion.

\section{RESEARCH METHOD}

\subsection{Model of a solar cell}

There are two popular types of cell models. The first model depends on one diode and it is called single-diode model $[20,21]$. While the second type depends on two diodes and it is called double-diode model [8]. However, the double-diode model has better accurate results, but it has too many complicated equations. The single-diode model has also accurate results and easier mathematical expressions [22]. Therefore, Villalva's algorithm is based on single diode model as in Figure 1.

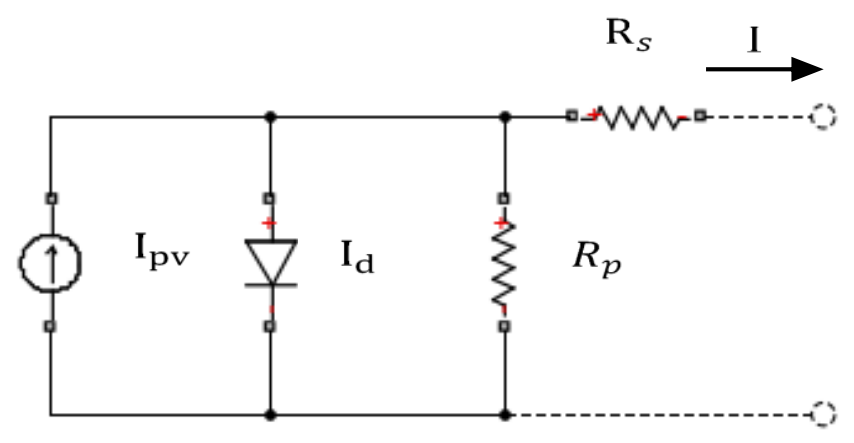

Figure 1. Practical solar cell model

Villalva's algorithm has many improvements for calculating the PV model parameters as will be clarified later. Therefore an accurate and reliable PV model can be obtained. This method depends mainly on finding the model parameters using three point in the I-V curve. The three points which are open circuit, short circuit and maximum power point are easily obtained by the data provided in datasheets under STCs. The I-V equation for a PV array is:

$$
I=I_{p v}-I_{o}\left[\exp \left(\frac{q\left(V+I R_{S}\right.}{a k T}\right)-1\right]-\frac{V+I R_{S}}{R_{p}}
$$

where $I_{p v}$ and $I_{o}$ are the photocurrent and the diode reverse saturation current, respectively, $q$ is the electron charge $\left(1.6 \times 10^{-19} \mathrm{C}\right), k$ is the Boltzmann constant $\left(1.38 \times 10^{-23} \mathrm{~J} / \mathrm{K}\right), a$ is the modified ideal factor, $R_{S}$ and $R_{p}$ are, respectively, the series and parallel resistance $(\Omega)$, and $T$ is the cell temperature $(\mathrm{K})$. The (1) is obtained from Figure 1 based on Kirchhoff's current law (KCL), where the diode current $I_{d}$ is substituted by;

$$
I_{d}=I_{o}\left[\exp \left(\frac{q\left(V+I R_{S}\right.}{a k T}\right)-1\right]
$$

Adjusting (1) at the three points can lead to find the unknown parameters $I_{p v}, I_{o}, R_{p}, R_{s}$, and $a$. $I_{p v}$ can be found by (3).

$$
I_{p v}=\left[I_{p v, n}-K_{i}\left(T-T_{n}\right)\right] \frac{G}{G_{N}}
$$

It is generally assumed $I_{p v}=I_{s c}$ (Short circuit current of the cell) because the $R_{s}$ is low and $R_{p}$ is high. The diode saturation current is normally expressed as [23]. 


$$
I_{o}=I_{o, n}\left(\frac{T_{n}}{T}\right)^{3} \exp \left[\frac{q E_{g}}{a K}\left(\frac{1}{T_{n}}-\frac{1}{T}\right)\right]
$$

The (4) can be replaced by (5) and provides an improvement for the PV model because the dependency on temperature is included using the voltage and current temperature coefficient $\left(K_{v}\right.$ and $\left.K_{i}\right)$ [24].

$$
I_{o}=\frac{I_{s c, n}+K_{i} \Delta T}{\exp \left[\left(V_{o c, n}+K_{v} \Delta T\right) / a V_{t}\right]-1}
$$

Finding $R_{p}$ and $R_{s}$ is done based on that there is a point where the model maximum power point $P_{\max , m}$ equals the datasheet maximum power point $P_{\max , e}$ as in (6) [24]. Adjusting the I-V equation by incrementing $R_{s}$ starts from zero and then finds $R_{p}$ by (7). Incrementing $R_{s}$ should be linearly with a small and fixed step increase in order to get the desired values of $R_{s}$ and $R_{p}$.

$$
\begin{aligned}
& P_{\text {max }, m}=V_{m p}\left\{I_{p v}-I_{o}\left[\exp \left[\frac{\left(V_{m p}+I_{m p} R_{s}\right)}{a N_{s}} \frac{q}{k T}\right]-1\right]-\frac{V_{m p}+I_{m p} R_{s}}{R_{p}}\right\}=P_{\text {max }, e} \\
& R_{p}=\frac{\left(V_{m p}+I_{m p} R_{S}\right)}{I_{p v}-I_{o} \exp \left[\frac{\left(V_{m p}+I_{m p} R_{S}\right) q}{a N_{S}} k T\right]+I_{o}-\frac{P_{m a x}, e}{V_{m p}}}
\end{aligned}
$$

Further improve is developed by [24] using (8) which warrants more accurate matching between model I-V curve and real PV array I-V curve so $I_{p v} \neq I_{s c}$.

$$
I_{p v, n}=\frac{R_{p}+R_{s}}{R_{p}} I_{s c, n}
$$

The initial value of $R_{s}$ is 0 while the intial value of $R_{p}$ is obtained by:

$$
R_{p, \min }=\frac{V_{m p}}{I_{s c, n}-I_{m p}}-\frac{V_{o c, n}-V_{m p}}{I_{m p}}
$$

\subsection{Proposed algorithm}

EFPPM is designed similar to Villalva's algorithm. However, in the designed EFPPM, dynamic incrementation is proposed instead of the static incrementation proposed in Villalva's algorithm. The dynamic incrementation is used to improve the speed of algorithm and reduces the computation time when finding the model parameters. The initial incrementation step in EFPPM is set to 0.1 ( 0.1 is considered a big step value because the value of $R_{S}$ is small). Incrementing continues until the value of $R_{S}$ jumps over the desired value. Then the last value of $R_{s}$ before exceeding the desired value will be increased using a new increment step (the new increment step=the previous increment step divided by 10). These processes continue until matching the $P_{\max , m}$ with $P_{\max , e}$. The ideas are to use a dynamic increment step for $R_{s}$ incrementation starting from a big value 0.1 until the best value of $R_{s}$ and $R_{p}$ are found. The static increment step is replaced by the dynamic increment step to reduce the iteration numbers of the modelling algorithm in [24]. Figure 2 shows the flowchart of the proposed EFPPM.

\section{RESULTS AND DISCUSSION}

EFPPM reduces the number of the iteration and has the same accuracy of the Villalva's algorithm. Reduction is done based on using dynamic incrementation. Table 1 shows the electrical characteristics of KC200GT solar array [25] provided by the datasheet. The KC200GT solar array is used here to create a PV model using EFPPM and the Villalva's algorithm and then makes a comparison between them.

Figures 3 and 4 show the I-V and P-V curves plotted for different values of $R_{s}$ and $R_{p}$ using both the Villalva's algorithm and EFPPM, respectively. As we notice, the plotted curves in Figures 3. (a) and (b) move toward left as $R_{s}$ is slowly increased. In Villalva's algorithm, $R_{s}$ starts from zero. The desired $R_{s}$ and $R_{p}$ are found when $P_{\max , m}$ matches with $P_{\max , e}$ using equation (6) as shown in Figure 3. (b). In Figures 4. (a) and (b), the plotted curves swing around MPP until the $P_{\max , m}$ matches with $P_{\max , e}$. Table 2 shows how $R_{s}$ is changed in EFPPM. The desired $R_{s}$ and $R_{p}$ are $0.221 \Omega$ and $415.76 \Omega$, respectively. Both methods the Villalva's algorithm and EFPPM produce same result of the desired $R_{s}$ and $R_{p}$ as shown in Figures 5. (a) 
and (b) but with different significant speed. They show that the model curves I-V and P-V exactly match with the experimental curves I-V and P-V of KC200GT solar array given by the datasheet at three points: short circuit point, MPP and open circuit point.

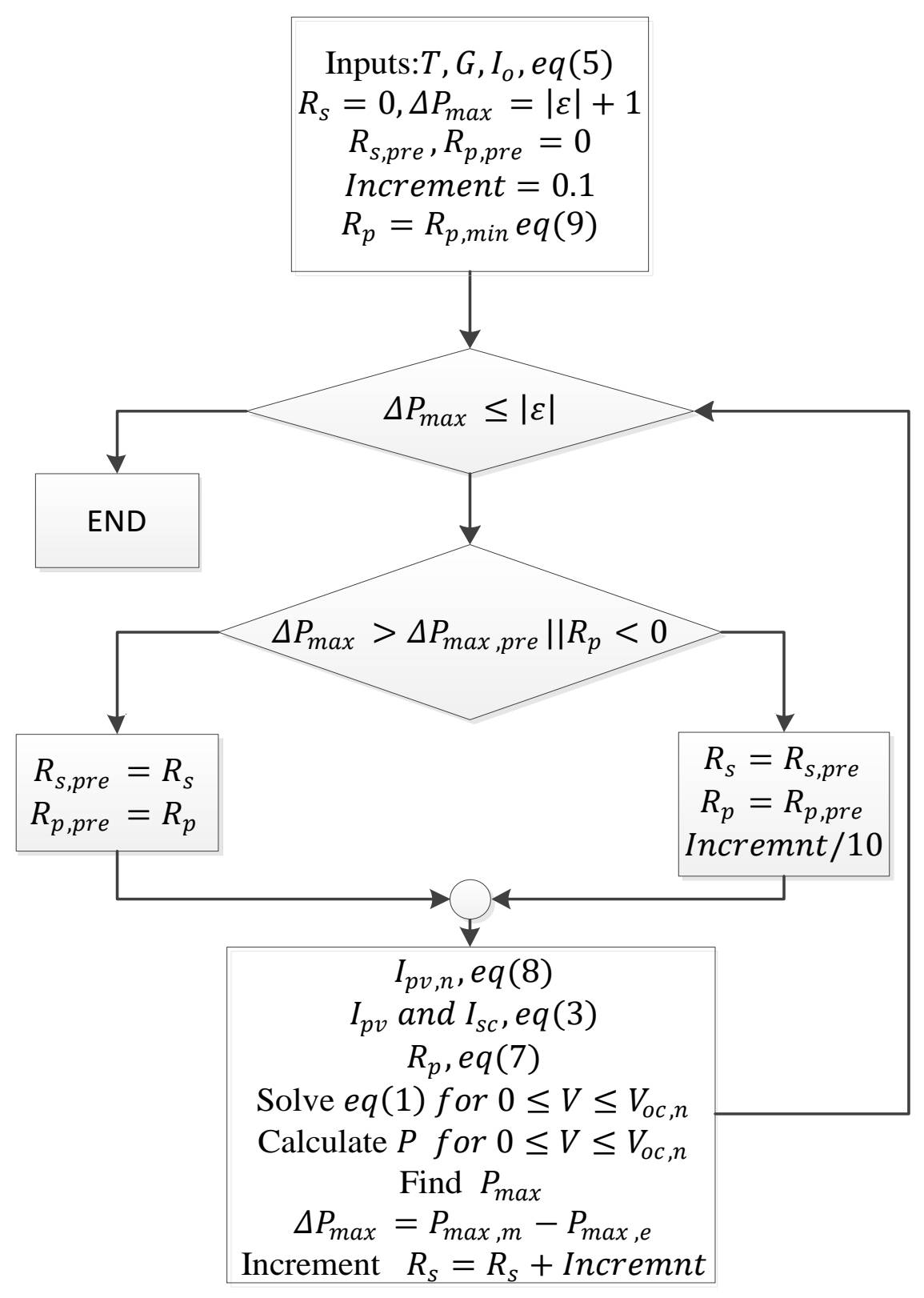

Figure 2. Flowchart of EFPPM

Table 1. Typical electrical characteristics of KC200GT module under STCs

\begin{tabular}{cc}
\hline parameter & value \\
\hline$P_{\max , e}$ & $200.143 \mathrm{~W}$ \\
$V_{m p}$ & $26.3 \mathrm{~V}$ \\
$I_{m p}$ & $7.61 \mathrm{~A}$ \\
$I_{s c, n}$ & $8.21 \mathrm{~A}$ \\
$V_{o c, n}$ & $32.9 \mathrm{~V}$ \\
$K_{i}$ & $0.0032 \mathrm{~A} / \mathrm{K}$ \\
$K_{v}$ & $-0.1230 \mathrm{~V} / \mathrm{K}$ \\
$\mathrm{Ns}$ & 54 \\
\hline
\end{tabular}




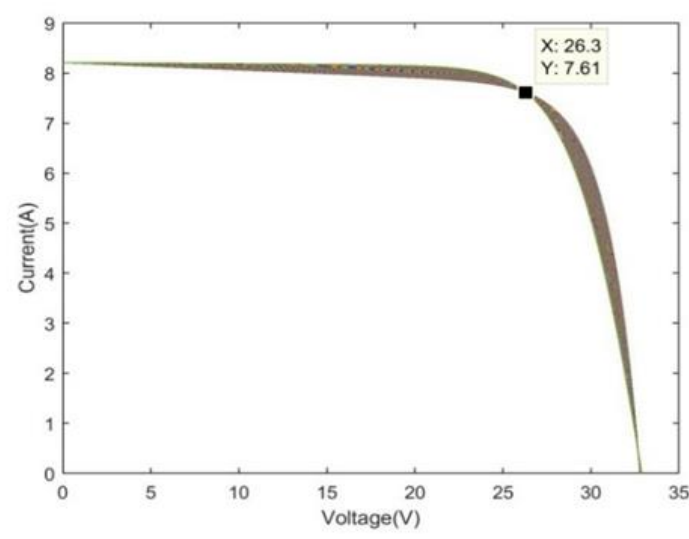

(a)

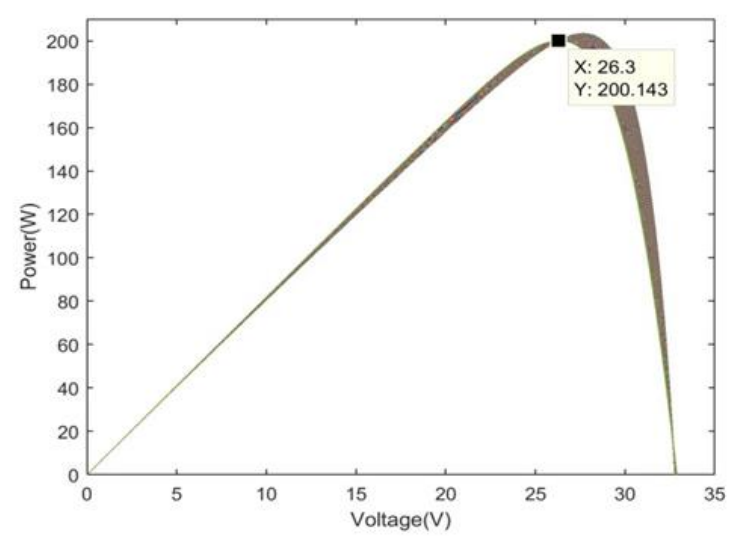

(b)

Figure 3. (a) I-V and (b) P-V curves plotted for many values of $R_{s}$ and $R_{p}$ for the Villalva's algorithm

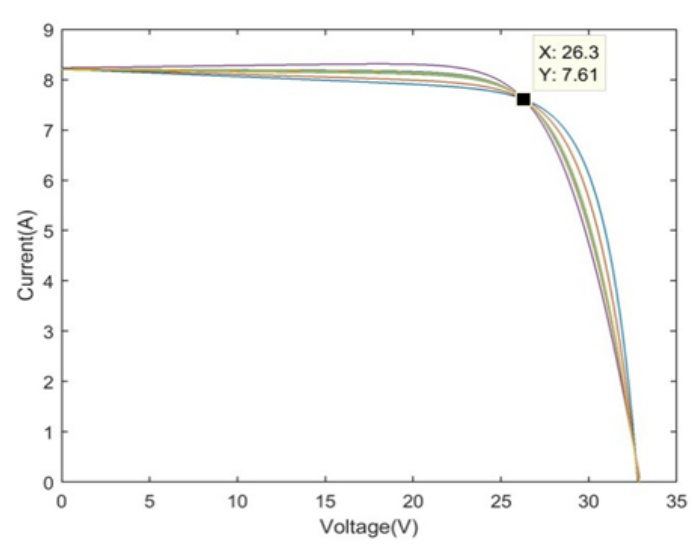

(a)

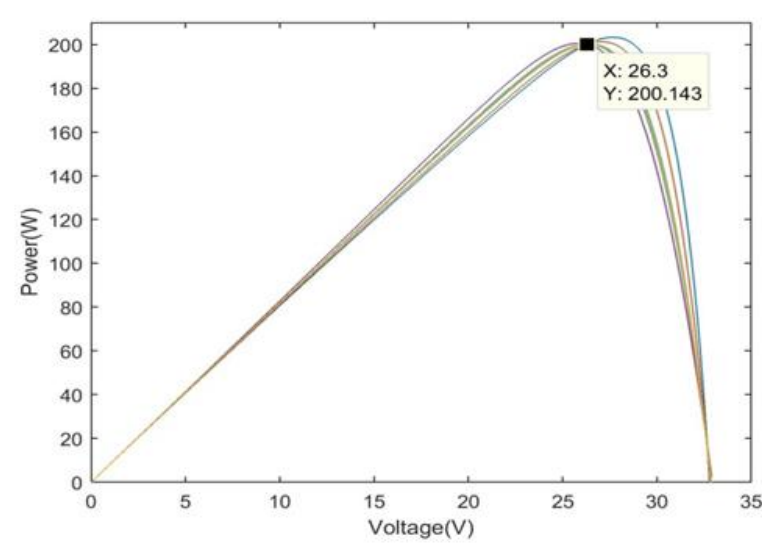

(b)

Figure 4. (a) I-V and (b) P-V curves plotted for many values of $R_{s}$ and $R_{p}$ for EFPPM

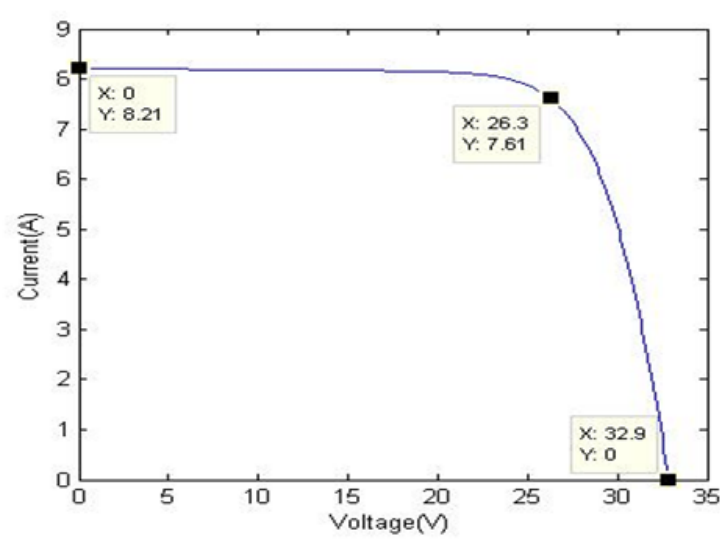

(a)

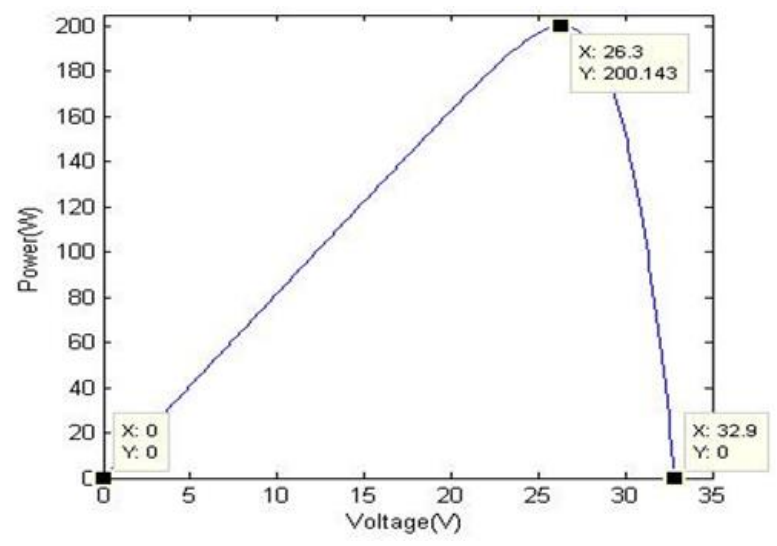

(b)

Figure 5. (a) I-V and (b) P-V curves plotted for the optimum value of $R_{s}$ and $R_{p}$ for both EFPPM and the Villalva's algorithm.

The number of plotted I-V and P-V curves until finding the optimum values of $R_{S}$ and $R_{p}$ using EFPPM is 10 while using the Villalva's algorithm is 221. In terms of computation time, EFPPM requires 5.7 Sec. when executed in the processor (2.0 GHz Intel Core 2 Duo T5800 compared to $123.4 \mathrm{sec}$. for Villalva's algorithm. This much time comes due to solving the nonlinear equation (1) for $\mathrm{I} \epsilon\left[0, I_{s c, n}\right]$ and $\mathrm{V} \epsilon\left[0, V_{o c, n}\right]$. 
$I_{s c, n}$ and $V_{o c, n}$ are 8.21 and 32.9, respectively. The values of $R_{S}$ used in the iteration process using EFPPM are listed in Table 2.

Table 2. $R_{\mathrm{S}}$ Incrementation values of EFPPM

\begin{tabular}{ccc}
\hline \multicolumn{3}{c}{$R_{S}$ Values } \\
\hline First Sequence & Second Sequence & Third Sequence \\
\hline 0 & 0.20 & 0.220 \\
0.1 & 0.21 & 0.221 \\
0.2 & 0.22 & \\
\hline
\end{tabular}

The desired parameters values with a comparison between EFPPM and the Villalva's algorithm in term of iteration no and computation time are listed in Table 3. The table shows that both methods give same result but different computation time. Table 3 shows the superiority for EFPPM against Villalva's algorithm in term of time efficiency. Lastly, despite of the high accuracy of Villalva's algorithm, it consumes too much time to find the five parameters of the PV modules. Therefore, we need a modelling algorithm that produces high accurate PV models with acceptable computation time and that is available in EFPPM. EFPPM can be more effective with large solar arrays that have large $R_{s}$, because the reduction of time computation done by EFPPM will be more noticeable.

Table 3. Parameters of the adjusted model of the Kc200gt solar array at nominal operating conditions

\begin{tabular}{ccc}
\hline Parameters & Villalva's algorithm [24] & EFPPM \\
\hline$P_{\text {max }, e}$ & $200.143 \mathrm{~W}$ & $200.143 \mathrm{~W}$ \\
$V_{m p}$ & $26.3 \mathrm{~V}$ & $26.3 \mathrm{~V}$ \\
$I_{m p}$ & $7.61 \mathrm{~A}$ & $7.61 \mathrm{~A}$ \\
$I_{s c, n}$ & $8.21 \mathrm{~A}$ & $8.21 \mathrm{~A}$ \\
$V_{o c, n}$ & $32.9 \mathrm{~V}$ & $32.9 \mathrm{~V}$ \\
$\mathrm{a}$ & 1.3 & 1.3 \\
$I_{p v}$ & $8.214 \mathrm{~A}$ & $8.214 \mathrm{~A}$ \\
$I_{o, n}$ & $9.8225 \mathrm{e}-08$ & $9.8225 \mathrm{e}-08$ \\
$R_{s}$ & 0.221 & 0.221 \\
$R_{p}$ & 415.78 & 415.78 \\
Iteration Num & 221 & $\mathbf{1 0}$ \\
Computation Time & 123.447 Seconds & $\mathbf{5 . 7 2 5}$ Seconds \\
\hline
\end{tabular}

\section{CONCLUSION}

Solar energy has some drawbacks such as high cost, recombination, shading, and day sunlight. Many researchers try to maximize the efficiency of photovoltaic system by studying the I-V and P-V characteristics curves. Mathematical modelling gives us an easy and accurate tool to analyse I-V and P-V characteristics curves. In this paper, the main objective is to overcome the slowness of the existing modelling algorithms. The proposed modelling algorithm (EFPPM) is a method to find the five unknown PV model parameters $(a$, $I_{o}, I_{p v}, R_{s}$, and $R_{p}$ ). Finding the $\mathrm{PV}$ model parameters is done based on adjusting the I-V curve in three points that are provided by datasheet (short circuit, open circuit, and MPP). An iterative process of increasing $R_{S}$ and then find $R_{p}$ and $I_{p v}$ is the main key to adjust the I-V curve. This iteration processes, based on fixed increment, consumes much time because of solving nonlinear equation. An improvement is fulfilled by minimizing the number of the iterations. Instead of using fixed increment to find the optimum values of PV model parameters, a dynamic increment is used. The time consumed to find the model parameters of KC200GT solar array is 5.725 seconds using EFPPM instead of 123.447 seconds using a similar work. This result shows that EFPPM has superiority in term of the computation time.

\section{ACKNOWLEDGEMENT}

The authors are grateful to Universiti Sains Malaysia (USM) for supporting this research through USM Short-Term Grant 304/PELECT/6315292. Many thanks also to Power Laboratories of School of Electrical and Electronic Engineering-USM, that has provided the research facilities and equipment/instruments to carry out this research project. 


\section{REFERENCES}

[1] Dunlop, J. P., "Photovoltaic Systems," Amer Technical Pub \& NJATC. 2nd edition, July 2009.

[2] IEA, O., World energy outlook 201. Vienna: IEA, pp. 672, November 2012.

[3] Nakanishi, H., I. Turksen, and M. Sugeno, "A review and comparison of six reasoning methods," Fuzzy sets and systems, vol. 57, no. 3, pp. 257-294, August 1993.

[4] Chaudhary, P., M. Rizwan, and M. T. Ahmad, "MATLAB/Simulink Based Modeling and Simulation of Photovoltaic Array," in International Conference of Advance Research and Innovation, 2014.

[5] Sudeepika, P. and G. M. G. Khan, "Analysis of mathematical model of PV Cell module in MATLAB/simulink environment," International Journal of Advanced Research in Electrical, Electronics and Instrumentation Engineering, vol. 3, no. 3, pp. 7823-7829, March 2014.

[6] G. Guo, X.W., S. Zhou, and B. Cao, "Modeling of solar photovoltaic cells and output characteristic simulation based on Simulink," Journal of Chemical and Pharmaceutical Research, vol. 6, no. 7, pp. 1791-1795, 2014.

[7] S. Chowdhury, G. A. Taylor, S. P. Chowdhury, A. K. Saha and Y. H. Song, "Modelling, simulation and performance analysis of a PV array in an embedded environment," 2007 42nd International Universities Power Engineering Conference, Brighton, pp. 781-785, 2007.

[8] J. A. Gow and C. D. Manning, "Development of a photovoltaic array model for use in power-electronics simulation studies," in IEE Proceedings - Electric Power Applications, vol. 146, no. 2, pp. 193-200, March 1999.

[9] J. A. Gow and C. D. Manning, "Development of a model for photovoltaic arrays suitable for use in simulation studies of solar energy conversion systems," 1996 Sixth International Conference on Power Electronics and Variable Speed Drives (Conf. Publ. No. 429), Nottingham, UK, pp. 69-74, 1996.

[10] Hyvärinen, J. and J. Karila, "New analysis method for crystalline silicon cells," 3rd World Conference on Photovoltaic Energy Conversion, 2003. Proceedings of, Osaka, vol. 2, pp. 1521-1524, 2003.

[11] N. Pongratananukul and T. Kasparis, "Tool for automated simulation of solar arrays using general-purpose simulators," 2004 IEEE Workshop on Computers in Power Electronics, 2004. Proceedings., Urbana, IL, USA, pp. 10-14, 2004.

[12] Nishioka, K., N. Sakitani, Y. Uraoka, et al., "Analysis of multicrystalline silicon solar cells by modified 3-diode equivalent circuit model taking leakage current through periphery into consideration," Solar Energy Materials and Solar Cells, vol. 91, no. 13, pp. 1222-1227, August 2007.

[13] Lorenzo, E., "Solar electricity: engineering of photovoltaic systems," Earthscan Publications Ltd, January 1994.

[14] Bai, J., S. Liu, Y. Hao, et al., "Development of a new compound method to extract the five parameters of PV modules," in Energy Conversion and Management, vol. 79, pp. 294-303, March 2014.

[15] Karatepe, E., M. Boztepe, and M. Colak, "Neural network based solar cell model," in Energy Conversion and Management, vol. 47, no. 9-10, pp. 1159-1178, June 2006.

[16] Zhang, L. and Y. F. Bai, "Genetic algorithm-trained radial basis function neural networks for modelling photovoltaic panels," in Engineering Applications of Artificial Intelligence, vol. 18, no. 7, pp. 833-844, October 2005.

[17] M. Abdul Hadi, A. M. Al-Ibrahim and G. S. Virk, "Neuro-fuzzy-based solar cell model," in IEEE Transactions on Energy Conversion, vol. 19, no. 3, pp. 619-624, Sept. 2004.

[18] D. Sera, R. Teodorescu and P. Rodriguez, "PV panel model based on datasheet values," 2007 IEEE International Symposium on Industrial Electronics, Vigo, pp. 2392-2396, 2007.

[19] A. H. Ali, H. S. Hamad, A. A. Abdulrazzaq, "Performance investigation of grid connected photovoltaic system modelling based on MATLAB simulation," in International Journal of Electrical and Computer Engineering (IJECE), vol. 8, no. 6, pp. 4847-4854, December 2018.

[20] M. A. Islam, A. Merabet, R. Beguenane and H. Ibrahim, "Modeling solar photovoltaic cell and simulated performance analysis of a 250W PV module," 2013 IEEE Electrical Power \& Energy Conference, Halifax, NS, pp. 1-6, 2013.

[21] R. H. Sagor and M. A. Abido, "Study of solar energy for PV implementation in Saudi Arabia," 2010 IEEE International Energy Conference, Manama, pp. 830-834, 2010.

[22] Carrero, C., J. Amador, and S. Arnaltes, "A single procedure for helping PV designers to select silicon PV modules and evaluate the loss resistances," in Renewable Energy, vol. 32, no. 15, pp. 2579-2589, December 2007.

[23] G. Vachtsevanos and K. Kalaitzakis, "A hybrid photovoltaic simulator for utility interactive studies," in IEEE Transactions on Energy Conversion, vol. EC-2, no. 2, pp. 227-231, June 1987

[24] M. G. Villalva, J. R. Gazoli and E. R. Filho, "Comprehensive approach to modeling and simulation of photovoltaic arrays," in IEEE Transactions on Power Electronics, vol. 24, no. 5, pp. 1198-1208, May 2009.

[25] KC200GT High Efficiency Multicrystal Photovoltaic Module Datasheet Kyocera. [Online]. Available: http://www.kyocera.com.sg/products/solar/ pdf/kc200gt.pdf 